\title{
Theoretical and Perceptual Market Values for Fresh Squeezed Orange Juice
}

\author{
Hyeyoung Kim (Corresponding author) \\ Food and Resource Economics Department, University of Florida \\ PO box 110240, Gainesville, FL, 32611, USA \\ Tel: 1-352-392-1826 E-mail:kim1978@ufl.edu
}

Lisa A. House

Food and Resource Economics Department, University of Florida

PO box 110240, Gainesville, FL, 32611, USA

Tel: 1-352-392-1826_E-mail: lahouse@ufl.edu

Zhifeng Gao

Food and Resource Economics Department, University of Florida

PO box 110240, Gainesville, FL, 32611, USA

Tel: 1-352-392-1826 E-mail: zfgao@ufl.edu

\author{
Received: February 14, 2012 Accepted: February 25, $2012 \quad$ Published: April 1, 2012 \\ doi:10.5539/ijms.v4n2p45 URL: http://dx.doi.org/10.5539/ijms.v4n2p45
}

Support for this research was provided by the Florida Department of Citrus. All mistakes are the responsibility of the authors.

\begin{abstract}
This study measures product differentiation effects from observing the fresh orange juice being squeezed on the willingness to pay for a glass of fresh juice. Both the Westendorp price sensitivity meter and a hypothetical choice experiment are used to estimate consumer willingness to pay. Results from the hypothetical choice model indicated when participants observed the process of squeezing fresh oranges to make juice, they were statistically willing to pay higher values not only for the fresh squeezed orange juice, but other types of orange juices as well. The van Westendorp method failed to pick up significant differences in willingness to pay for fresh, or other, juices. This may be due to the lack of theoretical grounding and incentive compatibility, leading to underestimating the value of the fresh squeezed orange juice.
\end{abstract}

Keywords: Choice experiment, Incentive compatibility, Fresh squeezed juices, Price sensitivity meter

\section{Introduction}

Orange juice has been the most consumed fruit juice in the United States. Annual per capita consumption averaged 4.8 gallons from 1990 to 2008, accounting for nearly 60 percent of total fruit juice consumption (USDAa). Recently, however, the trend has been a decrease in consumption of orange juice relative to other fruit juices (Figure 1). In 2008, the average per capita availability was 3.3 gallons, a 48 share of total fruit juice availability (USDAa). Though orange juice is still consumed by many people, it is typically an at-home drink. A 2003 study by the United States Department of Agriculture found that over 88 percent of consumers drink orange juice at home and only 2.8 percent consumed juice in restaurants (Pollack, Lin, and Allshouse, 2003). The three major types of orange juice distributed in the United States are: frozen concentrate orange juice (FCOJ); orange juice from concentrate (RECON), and not-from-concentrate orange juice (NFC). 
Of domestically produced orange juice, 90 percent is produced in Florida (USDAb). Given the importance of juice to the Florida citrus market, an investigation was conducted to determine if viewing the juice squeezing process would influence consumers to purchase fresh squeezed orange juice away from home (at restaurants). As the process of squeezing the oranges in front of customers could accentuate freshness, the effect may be comparable to the impact of promotion on orange juice consumption. Though consumers know what orange juice is, seeing the squeezing process at a restaurant could be treated as a new product introduction, adding freshness when compared to chilled orange juice. As a result, different elicitation methods can be used to investigate the market value and to test the viability of this product. This study was conducted to investigate if it would be a good marketing strategy for a group of restaurants to introduce a specially designed table-top juicer (Appendix) that would allow customers to watch the orange squeezing process. Study results will contribute in assisting restaurant owners who may be interested in knowing how much fresh squeezing of orange juice affects consumers' preference.

As this study focuses on measuring the effect of orange juice freshness, as demonstrated by viewing the squeezing process, on consumer demand for fresh squeezed juice at a restaurant, willingness to pay values were necessary. In this study, values for the fresh juice are generated using both a hypothetical choice experiment (CE) and the van Westendorp's price sensitivity meter (PSM). A hypothetical CE is based on random utility theory and derives willingness-to-pay (WTP) for new or current products, while van Westendorp's PSM is based on consumer perception. Although van Westendorp's PSM is used in empirical market research (Bailey 2001; Michels, Kurz-Levin, and Schmitz 2009), there is less research to discuss the values from it and evaluate its appropriateness. The goal of this study is to examine the product values generated from these two pricing methods using one dataset.

\subsection{Van Westendorp's Price Sensitivity Meter (PSM) Method}

Van Westendorp (1976) introduced a simple method to assess consumer price perceptions based on respondents' answers to four price-related questions. The questions ask respondents to identify four different price levels as follows:

1) At what price do you begin to perceive the product as so expensive that you would not consider buying it? (Too expensive)

2) At what price do you begin to perceive the product as so inexpensive that you would feel that the quality cannot be very good? (Too inexpensive)

3) At what price do you perceive that the product is beginning to get expensive, so that it is not out of the question, but you would have to give some thought to buying it? (Expensive)

4) At what price do you perceive the product to be a bargain - a great buy for the money? (Inexpensive)

To analyze the data from the PSM, cumulative frequency distributions are derived and plotted in order to specify the price perceptions. These four price lines provide four intercept points known as the: indifference price point (IPP), optimal price point (OPP), point of marginal cheapness (PMC), and point of marginal expensiveness (PME). These points are shown in Table 1. The IPP represents either the median price actually paid by consumers already in the market or the price of the product of a market leader. The OPP maximizes the number of people who would consider the offering. Van Westendorp (1976) noted that there are numerous cases in which the IPP and OPP are identical. Separate positions indicate some kind of "stress" in price consciousness (Gellynck and Viaene, 2002). The acceptable price range between PMC and PME contains the vast majority of all competitive offerings in a mature market (van Westendorp 1976). Lipovetsky (2006) extended van Westendorp models to statistical modeling with logistic regressions in order to improve applications of price sensitivity analysis. Desmet (2009) used the modified van Westendrop method to compute reference prices.

The main advantages of the PSM are that it is simple for both the respondent and the researcher. From a survey administration perspective, only asking four questions to generate pricing information is a low burden for respondents. However, there are potential drawbacks to this method. If respondents do not have a good reference price for the goods (for example because they do not have much experience with the product), the van Westendorp method often underestimates the products' ability to command premium prices (MarketVision Research). In addition, because the PSM is based on open-ended questions, the estimated product values may not be incentive compatible as they are based on open-ended questions (Horowitz and McConnell (2002); Frew, Whynes, and Wolstenholme (2003); Shaeffer et al. (2004)). Another issue with the PSM is the number of inconsistent price answers. As an internal validation check, prices from one respondent can be compared to ensure that prices for "too expensive" are higher than "too inexpensive" for example (all pairings can be 
compared to ensure validity). If a high number of inconsistent answers is found in a dataset, the results from the model would be doubtful, even if those observations are deleted.

\subsection{Discrete Choice Method}

Consumers' utility can be derived using CE because the experiments are based on random utility theory and are consistent with Lancaster's theory of utility maximization which states that consumers demand attributes embodied in a good (Louviere, Hensher, and Swait, 2000). Thus, CE contributes to achieving marketing goals efficiently by helping to identify what types of product attributes (for example, freshness) consumers prefer or avoid. The random utility model represents the fundamental approach for the consumer choices with multinomial discrete choice. Let $U_{i j}$ be the $i$ th consumer's utility of choosing $j$ th alternative. This total utility can be divided into two components: a systematic component, $V_{i j}$, and a random component, $\varepsilon_{i j}$.

$$
U_{i j}=V_{i j}+\varepsilon_{i j}
$$

Assuming the random component, $\varepsilon_{i j}$ is independently identically distributed (i.i.d.) with type I extreme value (Gumbel) distribution leading to a logit model formulation (McFadden, 1974) known as the multinomial logit model (MNL). The probability of consumer $i$ choosing alternative $j$ out of a total of $\mathrm{J}$ options is

$$
P(i=j)=\frac{\exp \left(V_{i j}\right)}{\sum_{k=1}^{J} \exp \left(V_{i j}\right)}
$$

where $\mathrm{j}=1,2, \ldots, \mathrm{J}$

In this application, the systematic portion of the utility function can be expressed as linear from:

$$
V_{i j}=\alpha_{j}+\alpha_{p} P_{i j}+\gamma_{i}\left(P_{i j} \times W_{i}\right)
$$

where $\alpha_{j}$ is an alternative-specific constant (ASC) representing the mean of the distributions of the unobserved effects associated with alternative $j, \alpha_{p}$ is the marginal utility of price for people who do not see the squeezing process, $P_{i j}$ of alternative $j$ for consumer $i, \alpha_{p}+\gamma_{i}$ represents the marginal utility of price for individuals watching orange juice squeezing process, and $W_{i}$ is a dummy variable for watching the process $(=1)$ or not $(=0)$. Since we do not know the individual's tastes after watching the squeezing process of fresh orange juice, heterogeneous preferences are assumed. The coefficient $\gamma_{i}$ is assumed to be a random coefficient represented as:

$$
\gamma_{i}=\bar{\gamma}+\sigma \eta_{i}
$$

Where $\bar{\gamma}$ and $\sigma$ are the population mean and standard deviation of the coefficient $\gamma_{i}$, respectively, and $\eta_{i}$ is a stochastic term distributed normally with zero mean and standard deviation one. Hence, the probability of choosing alternative $j$ is estimated using a random parameter logit model.

Total WTP to purchase alternative $j$ versus the base alternative (i.e."no purchase") is calculated as the negative of the ratio of the alternative specific constant to the price coefficients for people who did not watch the squeezing process: $-\frac{\alpha_{j}}{\alpha_{p}}$.

Marginal WTP is obtained by subtracting total WTP for orange juice $j$ from total WTP for orange juice $k: \quad-\frac{\alpha_{j}}{\alpha_{p}}+\frac{\alpha_{k}}{\alpha_{p}}$.

A random parameter logit (RPL) model relaxes the assumption of independence from irrelevant alternatives (IIA) by modeling preference heterogeneity. Significant standard deviation of the coefficient implies the utility is correlated across alternatives. Chang, Lusk, and Norwood (2009) predicted retail shopping behaviors in three different product categories (ground beef, wheat flour, and dishwashing liquid) where three preference methods (hypothetical choices, non-hypothetical choices, and non-hypothetical rankings) and three discrete-choice methods (the multinomial logit (MNL), the independent availability logit, and the random parameter logit (RPL)) were compared with using mean square error and out of sample log-likelihood function values. They found that analyzing MNL or RPL with non-hypothetical rankings data provided the best forecasts.

The benefit of CEs being less subject to hypothetical bias has spurred its application in both private and public goods. Carlsson and Martinsson (2001) supported CE as demonstrating no statistically significant differences between hypothetical and non-hypothetical response in terms of marginal WTP. Lusk and Schroeder (2004) found that hypothetical experiments tended to predict higher probabilities of purchasing (or willingness-to-pay) than non-hypothetical responses in total WTP, but that this hypothetical bias does not influence the marginal 
WTP. However, a potential drawback of the CE method is depending on the number of attributes considered, the number of choices that need to be presented to respondents can be high. Either block designs must be implemented, increasing the sample size (and cost), or respondents may face a high burden of answering questions.

\section{Experimental Methods for Evaluating Orange Juice Freshness}

A mall intercept survey was conducted with a random sample of consumers recruited by a market research firm. Participants were recruited in two malls located in Tampa and Orlando, Florida and were required to be adult primary grocery shoppers, who had consumed orange juice within the last thirty days. Participants were divided into two groups; half watched the orange-squeezing process prior to tasting the juices (group A) and the other half tasted the juices without watching the juicing process (group B). All participants rated sensory properties of fresh squeezed, not-from concentrate (NFC), and from concentrate.

Following the sensory (taste) test, participants responded to price perception questions for fresh squeezed orange juice and answered hypothetical choice experiment questions for the three different types of orange juice with different combinations of price levels. Prices for the hypothetical choice experiments ranged from $\$ 1.99$ to $\$ 5.49$ per $10 \mathrm{oz}$. glass. An example of the format for the questions in which participants were asked to select one of four options including a "no purchase" option is shown in Table 2. Price restrictions were imposed to more accurately reflect choices in the market such that fresh squeezed orange juice and NFC did not include the \$1.99 price level, and NFC and from concentrate did not include the highest level (\$5.49). \$4.49 was also excluded as an option for from concentrate.

\section{Results}

Surveys were conducted in Tampa and Orlando, Florida ( $n=100$ each) in June 2009. Of the 200 participants, 52 percent were men and 48 percent were female. Average participants have $\$ 30,000$ to $\$ 49,999$ annual income, an average household size of 3 people, and over 65 percent had some university or high school education. Participants' ages were distributed such that 37 percent were less than or equal to 30 years old, 40 percent were between 31 and 50 years old, and 24 percent were over 51 years old. A more detailed description of the sample, separated by group (did or did not observe the orange squeezing process) is shown in Table 3. In the final column in Table 3, data from the U.S. Census for Florida are listed (U.S. Census Bureau, 2012). The sample for this survey tended to include younger families, which may be in part due to the requirement of having purchased orange juice recently. Overall 43 percent of the total participants had purchased orange juices at restaurant, juice bar, or coffee shop at least one time in the past 6 months, implying the validity of the price data collected from the sample as they should be aware of reference points.

\subsection{Results of van Westendorp's Price Sensitivity Meter}

Prior to analysis of the van Westendorp data, the data was cleaned for inconsistent observations. Eighteen observations indicated prices for "too expensive" that were less than they indicated for "expensive" and 37 observations showed prices for "too inexpensive" that were more than they indicated for "inexpensive". Nine observations indicated invalid combinations in both cases. In addition, an observation including a negative price for "too inexpensive" was not included. In total, $23 \%$ of observations were invalid. This high rate of inconsistent responses calls into question this method of pricing.

Average prices for the total sample and segmented samples according to the four price levels are shown in Table 4. The average price for "too expensive" is $\$ 3.46, \$ 0.98$ higher than the "expensive" price $(\$ 2.48)$. The average price for "too inexpensive" is $\$ 1.06$ which is $\$ 0.59$ lower than the "inexpensive" price $(\$ 1.65)$. Group A (observed juicing process) reported slightly higher prices, but a two sample t-test indicated no statistically significant difference between the groups. Though the average prices were not statistically different, the variances were. There were wider variations for those who observed the squeezing process compared to those who did not. This indicates that observation of the squeezing process results in more heterogeneous responses among observed participants.

Cumulative percentages are shown in Figures 2 and 3. The acceptable price range for overall observations is $\$ 1.50$ to $\$ 2.19$ between the PMC and PME in Figure 2. This study found that the two points IPP and OPP are approximately $\$ 2.00$, indicating there is a small relevant range of pricing. This is not unexpected as one could view the orange juice market as a market with homogeneity in which many people purchase the product. The acceptable price range for those who observed the squeezing process is $\$ 1.59$ to $\$ 2.49$, a 90 cent range, compared to a 59 cent range ( $\$ 1.50$ to $\$ 2.09$ ) for those who did not observe the squeezing process (Figure 3). The point of PMC is similar for both groups but the location of the upper point, PME varies significantly. This 
implies that while observing machine squeezing does not affect the marginal cheapness points, it does move the marginally expensive border further out. Therefore, people who watched the squeezing process tended to have more positive perceptions. In summary, participants' reaction to observing the juicer as a method of product differentiation varies within the group.

\subsection{Results of Random Parameter Logit Model}

Estimates from the RPL models in Eq. 3 are shown in Table 5. The price coefficient for orange juice is negative implying that a higher price is associated with a lower likelihood of purchase as expected in economic theory. The positive alternative specific constants indicate that the utility of purchasing one of the products, fresh orange juice, NFC, and from concentrate is higher than no purchase. Likelihood ratio tests also support the significance of goodness of fit for the model which shows that the hypothesis of zero parameters is rejected at the $1 \%$ significance level. Preference heterogeneity can be proved from statistically significant mean and standard deviations of the price variable of those who observed the juice squeezing process. Average participants observing the squeezing process were likely to pay more not only for fresh-squeezed orange juice, but also for other orange juices. In this experiment, allowing potential consumers to observe the juice squeezing process may positively influence the value of all types of orange juice.

Orange juice premiums from observing the squeezing process range from $\$ 0.10$ to $\$ 0.17$ per $10 \mathrm{oz}$. serving (Table 6). The fresh squeezed orange juice gets the largest premiums from the marketing strategy; that is, there are larger differences in WTP between those observing fresh squeezing of orange juice and those not observing. However, NFC also had a larger WTP for those observing the fresh squeezing of orange juice. Participants observing the squeezing process were willing to pay $\$ 3.67, \$ 2.98$, and $\$ 2.21$ to purchase a 10 oz. serving of fresh orange juice, NFC, and from concentrate, respectively, relative to the "no purchase" option. The marginal WTP for fresh squeezed juice over NFC is $\$ 0.69$ and for NFC over from concentrate is $\$ 0.77$, indicating a slightly larger gap in quality between NFC and from concentrate than NFC and fresh squeezed.

The use of a portable juice squeezing machine that allows consumers to watch (and smell) the juice making process as a differentiation strategy increases the value of orange juice by $4.7 \%$, which is slightly higher than the advertising effect of $3.3 \%$ observed by Capps, Bessler and Williams (2004, p. 91). However, to accurately evaluate the effect of introducing a juicer, we should consider the price elasticity of orange juice because, in contrast to generic, the cost of installing and maintaining the machine would fall directly on the restaurant, hence reflecting an increase in selling prices. Kim, Ward, and Lee (2008) found own price elasticity of NFC ranging from -0.882 to -1.397 and Brown (1986) estimated own price elasticity of orange juice at -1.391 . Due to the relative elasticity of own price elasticity, the effect of marketing strategies that directly increase the product's price may be offset by decreases in demand.

WTP as calculated by the CE model for participants who observed the squeezing process is comparable to the "too expensive" price level in the van Westendorp PSM, implying that WTP may indicate the highest price perception of products as its definition; the maximum amount an individual would be willing to pay (Hanemann 1991). Compared to CE, the van Westendorp method slightly underestimated the value of fresh orange juice in both groups who observed and who did not observe the juicer, which may reflect the lack of incentive compatibility.

\section{Conclusions}

Both a hypothetical choice experiment and the van Westendorp price sensitivity meter were used to study the impact of a product differentiation strategy by demonstrating fresh squeezing of oranges in front of consumers who were asked about prices for orange juice. Fresh squeezed orange juices were preferred to NFC and from concentrate juices. The demonstration of the squeezing process increased not only the values of fresh squeezed orange juice, but also the values of NFC and from concentrate. People who watched the squeezing process had heterogeneous preferences and WTP increased by $4.7 \%$. The premium for fresh squeezed orange juice was almost double that of NFC. Though we found a higher WTP, this does not take into account the potential reaction of demand. Given previous studies finding orange juice demand is elastic, an increase in price, which would be expected given an increase in costs (from the addition of a juicer and related labor), may not result in increases in revenue.

Our findings indicate that the van Westendorp PSM underestimated prices, likely due to the lack of incentive compatibility, descriptive methods that are not driven by consumer behavior, and a high rate of inconsistency. Although Gellyunck and Viaene (2002) found that the acceptable price range from PSM for on-farm processed yogurt was similar to price settings from conjoint analysis, the study was limited to comparison of product values from PSM to conjoint analysis due to lack of information on WTP. The PSM only provided the different 
price distributions between two groups as shown in CE results. The CE results provide statistically significant differences of consumer preferences toward observing the squeezed processing and evaluated the values at 2 to 5 percent more than van Westendorp method.

A final note should address limitations of this research. Given the sample is not fully representative of demographics, the amounts generated from willingness to pay would not necessarily be representative of the full population. However, given the same sample was used to test both methods, the difference found between the van Westendorp and CE methods would not be impacted by this potential selection bias.

\section{References}

Bailey, W. M. (2001). A Pricing Strategy for the Kennedy Space Center Visitor Complex. Quirk's Marketing Research Review. [Online] Available: http://www.quirks.com/articles/a2001/20010508.aspx?searchID=246672100 (October 4, 2011)

Brown. M. G. (1986). The Demand for Fruit Juices: Market Participation and Quantity Demanded. Western Journal of Agricultural Economics, 11(2), 179-183.

Capps, O. Jr., Bessler, D. A., and Williams, G. W. (2004). Advertising and the Retail Demand for Orange Juice. TAMRC Consumer and Product Research Report No. CP-02-04.

Carlsson, F., and Martinsson, P. (2001). Do Hypothetical and Actual Marginal Willingness to Pay Differ in Choice Experiments? Journal of Environmental Economics and Management, 41(2), 179-192. http://dx.doi.org/10.1006/jeem.2000.1138

Chang, J. B., Lusk, J. L., and Norwood, F. B. (2009). How Closely Do Hypothetical Surveys and Laboratory Experiments Predict Field Behavior? American Journal of Agricultural Economics, 91(2), 518-534. http://dx.doi.org/10.1111/j.1467-8276.2008.01242.x

Desmet, P. (2009). Customer-based brand equity and price acceptability: an empirical analysis. Paper presented at the Australian and New Zealand Marketing Academy (ANZMAC) Conference, Melbourne, Australia.

Frew, E. J., Whynes, D. K., and Wolstenholme, J. L. (2003). Willingness to Pay: Comparing Closed-Ended with Open-Ended and Payment Scale Formants. Medical Decision Making, 23(2), 150-159. http://dx.doi.org/10.1177/0272989X03251245

Gellynck, X., and Viaene, J. (2002). Market-orientated Positioning of On-farm Processed Foods as a Condition for Successful Farm Diversification. Journal of Agricultural Economics, 53(3), 531-548. http://dx.doi.org/10.1111/j.1477-9552.2002.tb00036.x

Hanemann, W. M. (1991). Willingness to Pay and Willingness to Accept: How Much Can They Differ?' The American Economic Review, 81(3), 635-647.

Horowitz, J. K., and McConnell, K. E. (2002). Review of WTA/WTP Studies. Journal of Environmental Economics and Management, 44(3), 426-447. http://dx.doi.org/10.1006/jeem.2001.1215

Kim, H. Y., Ward, R. W., and Lee, J. Y. (2008). Impact of Features and Display Ads on the Demand for Orange Juice: An Extension of the Rotterdam Demand Model. Paper presented at the annual meeting of the American Agricultural Economics Association, Orlando, Florida, US. http://ageconsearch.umn.edu/handle/6070

Lipovetsky, S. (2006). Van Westendorp price sensitivity in statistical modeling. International Journal of Operations and Quantitative Management, 12(2), 141-156.

Louviere, J. J., Hensher, D. A., and Swait, J.D. (2000). Stated Choice Methods: Analysis and Application. (New York, US: Cambridge University Press.

Lusk, J. L., and Schroeder, T. C. (2004). Are Choice Experiments Incentive Compatible? A Test with Quality Differentiated Beef Steaks. American Journal of Agricultural Economic, 86(2), 467-482. http://dx.doi.org/10.1111/j.0092-5853.2004.00592.x

MarketVision Research. Van Westendorp: Price Sensitivity Meter [Online] Available: http://www.mv-research.com/pdfs/pricing.pdf (October 4, 2011).

McFadden, D. (1974). Conditional Logit Analysis of Qualitative Choice Behavior. In P. Zarembka (eds.), Frontiers in Econometrics. New York, US: Academic Press.

Michels, S., Kurz-Levin, M., and Schmitz, C. (2009). Off-label drug use - price analysis for Avastin in ophthalmology. International Journal of Pharmaceutical and Healthcare Marketing, 3(1), 59-73. http://dx.doi.org/10.1108/17506120910948511 
Pollack, S. L., Lin, B. H., and Allshouse, J. (2003). Characteristics of U.S. Orange Consumption. United States Department of Agriculture, FTS 305-01.

Shaeffer, E., Lampron, S., Krosnick, J., Tompson, T., Visser, P., and Hanemann, W. M. (2004). A Comparison of Open vs. Closed Survey Questions for Valuing Environmental Goods. Paper presented at the annual meeting of the American Association for Public Opinion Research, Pointe Hilton Tapatio Cliffs, Phoenix, Arizona, US.

U.S. Census Bureau. (2012). American Factfinder.

U.S. Department of Agriculture (USDAa). (2010). Food Availability Spreadsheets: Fruit Juices. Economic Research Service, USDA, Washington, D.C.

U.S. Department of Agriculture (USDAb). (2010). Fruit and Tree Nut Yearbook. Economic Research Service, USDA, Washington, D.C.

Westendorp (van), P. H. (1976). NSS-Price sensitivity meter: A new approach to study consumer perceptions of prices, ESOMAR (European Society for Opinion and Marketing Research) Congress, Venice, Italy. 139-167.

Table 1. Van Westendorp's price measurement points

\begin{tabular}{|c|c|c|}
\hline & Inexpensive & Too Inexpensive \\
\hline Expensive & $\begin{array}{l}\text { Indifference Price Point (IPP) } \\
\text { The number of respondents who consider the } \\
\text { product inexpensive or a bargain = the number } \\
\text { of respondents who consider it to be getting } \\
\text { expensive, but still worth considering. }\end{array}$ & $\begin{array}{l}\text { Point of Marginal Cheapness (PMC) } \\
\text { The number of respondents who find the price } \\
\text { too cheap = the number of people who at each } \\
\text { price point would find the price "not a } \\
\text { bargain." }\end{array}$ \\
\hline $\begin{array}{c}\text { Too } \\
\text { Expensive }\end{array}$ & $\begin{array}{l}\text { Point of Marginal Expensiveness (PME) } \\
\text { The number of respondents who find the price } \\
\text { too expensive = the number of respondents } \\
\text { who at each price point would find the price } \\
\text { "not expensive." }\end{array}$ & $\begin{array}{l}\text { Optimal Price Point (OPP) } \\
\text { The number of respondents who reject the } \\
\text { product as too expensive }=\text { the number of } \\
\text { respondents who reject it for being too cheap. }\end{array}$ \\
\hline
\end{tabular}

Table 2. Examples of questions for the hypothetical choices

\begin{tabular}{|c|c|c|c|}
\hline Features & Option 1 & Option 2 & Option 3 \\
\hline Type of Orange Juice & Fresh Squeezed & $\begin{array}{c}\text { Fresh chilled, } \\
\text { not from concentrate }\end{array}$ & From concentrate \\
\hline Size & 10 oz. glass & 10 oz. glass & 10 oz. glass \\
\hline Price & $\$ 5.49$ & $\$ 3.49$ & $\$ 1.99$ \\
\hline $\begin{array}{c}\text { Purchase } \\
\text { (select one only) }\end{array}$ & $\square$ & $\square$ & $\square$ \\
\cline { 2 - 4 } & \multicolumn{3}{|c|}{ ( No purchase } \\
\hline
\end{tabular}

* A picture of a glass of orange juice was shown with the choices to focus the participant on the $10 \mathrm{oz}$. serving. 
Table 3. Sample descriptions

\begin{tabular}{|c|c|c|c|c|}
\hline Variable & Variable description & $\begin{array}{c}\text { Group A } \\
(\mathrm{N} 1=100) \\
\%\end{array}$ & $\begin{array}{c}\text { Group B } \\
(\mathrm{N} 2=100) \\
\%\end{array}$ & $\begin{array}{c}\text { Florida } \\
\text { Census } \\
\%\end{array}$ \\
\hline \multirow[t]{2}{*}{ Gender } & Male & 56.0 & 48.0 & 48.3 \\
\hline & Female & 44.0 & 52.0 & 51.7 \\
\hline \multirow[t]{4}{*}{ Education } & HS & 48.0 & 39.0 & 44.4 \\
\hline & Some college & 37.0 & 53.0 & 29.7 \\
\hline & College degree & 9.0 & 5.0 & 16.6 \\
\hline & Post graduate & 4.0 & 3.0 & 9.2 \\
\hline \multirow[t]{5}{*}{ Income } & Under $\$ 30,000$ & 16.0 & 18.0 & 33.3 \\
\hline & $\$ 30,000$ to $\$ 49,999$ & 46.0 & 37.0 & 21.8 \\
\hline & $\$ 50,000$ to $\$ 74,999$ & 18.0 & 22.0 & 18.3 \\
\hline & $\$ 75,000$ to $\$ 99,000$ & 3.0 & 7.0 & 10.7 \\
\hline & $\$ 100,000$ or more & 7.0 & 2.0 & 15.8 \\
\hline No children & Yes & 46.6 & 47.0 & 25.4 \\
\hline \multirow[t]{3}{*}{ Age } & Less than equal to 30 & 42.0 & 31.0 & 19.7 \\
\hline & Between 31 and 50 & 37.0 & 42.0 & 33.4 \\
\hline & Over 51 & 21.0 & 27.0 & 46.9 \\
\hline \multicolumn{2}{|c|}{ Drinking 3 glasses more a week } & 77.0 & 80.0 & NA \\
\hline \multirow[t]{3}{*}{ Drink } & Fresh squeezed juice & 20.0 & 18.0 & NA \\
\hline & Not from concentrated & 58.0 & 54.0 & NA \\
\hline & From concentrated & 15.0 & 21.0 & NA \\
\hline \multicolumn{2}{|c|}{ Place to buy Restaurant, juice bar, and coffee shop } & 47.0 & 39.0 & NA \\
\hline \multicolumn{2}{|c|}{ Grocery, convenience, health store, vending machine } & 94.0 & 98.0 & NA \\
\hline
\end{tabular}

Table 4. Results of van Westendorp price sensitivity meter

\begin{tabular}{|c|c|c|c|c|}
\hline & $\begin{array}{l}\text { Average } \\
(n=153)\end{array}$ & $\begin{array}{c}\text { Observed Machine } \\
\text { Average ( } \mathrm{n}=74) \\
\mu_{\text {group A }}\end{array}$ & $\begin{array}{l}\text { Did not Observed } \\
\text { Machine Average } \\
\qquad(\mathrm{n}=79) \\
\mu_{\text {group B }}\end{array}$ & $\begin{array}{c}\text { Satterthwaite t-test } \\
\text { (Unequal variances) } \\
\text { Ho: } \mu_{\text {group A }}=\mu_{\text {group B }}\end{array}$ \\
\hline \multirow{2}{*}{ Too Expensive } & $\$ 3.46$ & $\$ 3.60$ & $\$ 3.33$ & \multirow{2}{*}{-0.84} \\
\hline & $(1.96)^{\mathrm{a}}$ & $(2.47)$ & $(1.31)$ & \\
\hline \multirow{2}{*}{ Expensive } & $\$ 2.48$ & $\$ 2.55$ & $\$ 2.41$ & \multirow{2}{*}{-0.70} \\
\hline & $(1.27)$ & $(1.54)$ & $(0.94)$ & \\
\hline \multirow{2}{*}{ Inexpensive } & $\$ 1.65$ & $\$ 1.77$ & $\$ 1.54$ & \multirow{2}{*}{-1.57} \\
\hline & $(0.87)$ & $(0.97)$ & $(0.75)$ & \\
\hline \multirow{2}{*}{ Too Inexpensive } & $\$ 1.06$ & $\$ 1.14$ & $\$ 0.99$ & \multirow{2}{*}{-1.32} \\
\hline & $(0.67)$ & $(0.83)$ & $(0.46)$ & \\
\hline
\end{tabular}

${ }^{\mathrm{a}}$ Numbers in parentheses are standard deviation. 
Table 5. Random parameter Logit models estimates

\begin{tabular}{|c|c|c|}
\hline & Parameter & Standard Error \\
\hline Fresh OJ & $4.2^{* * \mathrm{a}}$ & $(0.22)$ \\
\hline NFC & $3.41^{* *}$ & $(0.21)$ \\
\hline From concentrate & $2.54^{* *}$ & $(0.17)$ \\
\hline Price & $-1.2^{* *}$ & $(0.06)$ \\
\hline Price $\times$ Watch_mean & $0.06^{*}$ & $(0.03)$ \\
\hline Price $\times$ Watch_std. dev. & $0.34^{* *}$ & $(0.08)$ \\
\hline Log-likelihood at convergence & -2407 & \\
\hline Likelihood Ratio & 731.33 & \\
\hline Likelihood ratio index (LRI) & 0.1319 & \\
\hline Number of observations & 2000 & \\
\hline
\end{tabular}

${ }^{\mathrm{a}}$ Two asterisks $\left({ }^{* *}\right)$ indicates values that are statistically significant at the 0.05 level and one asterisk denotes values that are statistically significant at the 0.10 level.

Table 6. Total and marginal willingness-to-pay for orange juice

\begin{tabular}{|c|c|c|c|}
\hline & Observed Machine & Did not Observed Machine & Differences \\
\hline \multicolumn{4}{|c|}{ Total willingness-to-pay } \\
\hline Fresh OJ versus not to buy & $\$ 3.67$ & $\$ 0.17$ \\
\hline NFC versus not to buy & $\$ 2.98$ & $\$ 2.84$ & $\$ 0.14$ \\
\hline From concentrate versus not to buy & $\$ 2.21$ & $\$ 2.11$ & $\$ 0.10$ \\
\hline \multicolumn{5}{|c|}{ Marginal willingness-to-pay } & $\$ 0.66$ & $\$ 0.03$ \\
\hline Fresh OJ versus NFC & $\$ 0.69$ & $\$ 1.38$ & $\$ 0.07$ \\
\hline Fresh OJ versus From concentrate & $\$ 1.45$ & $\$ 0.73$ & $\$ 0.04$ \\
\hline
\end{tabular}




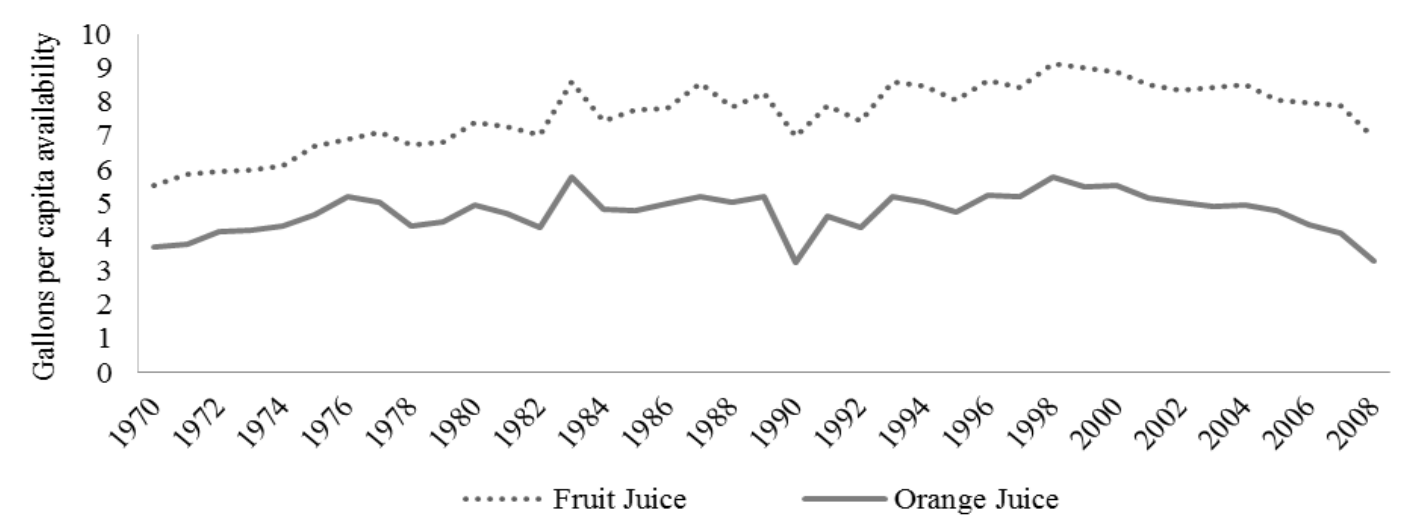

Figure 1. Per capita availability of fruit and orange juice

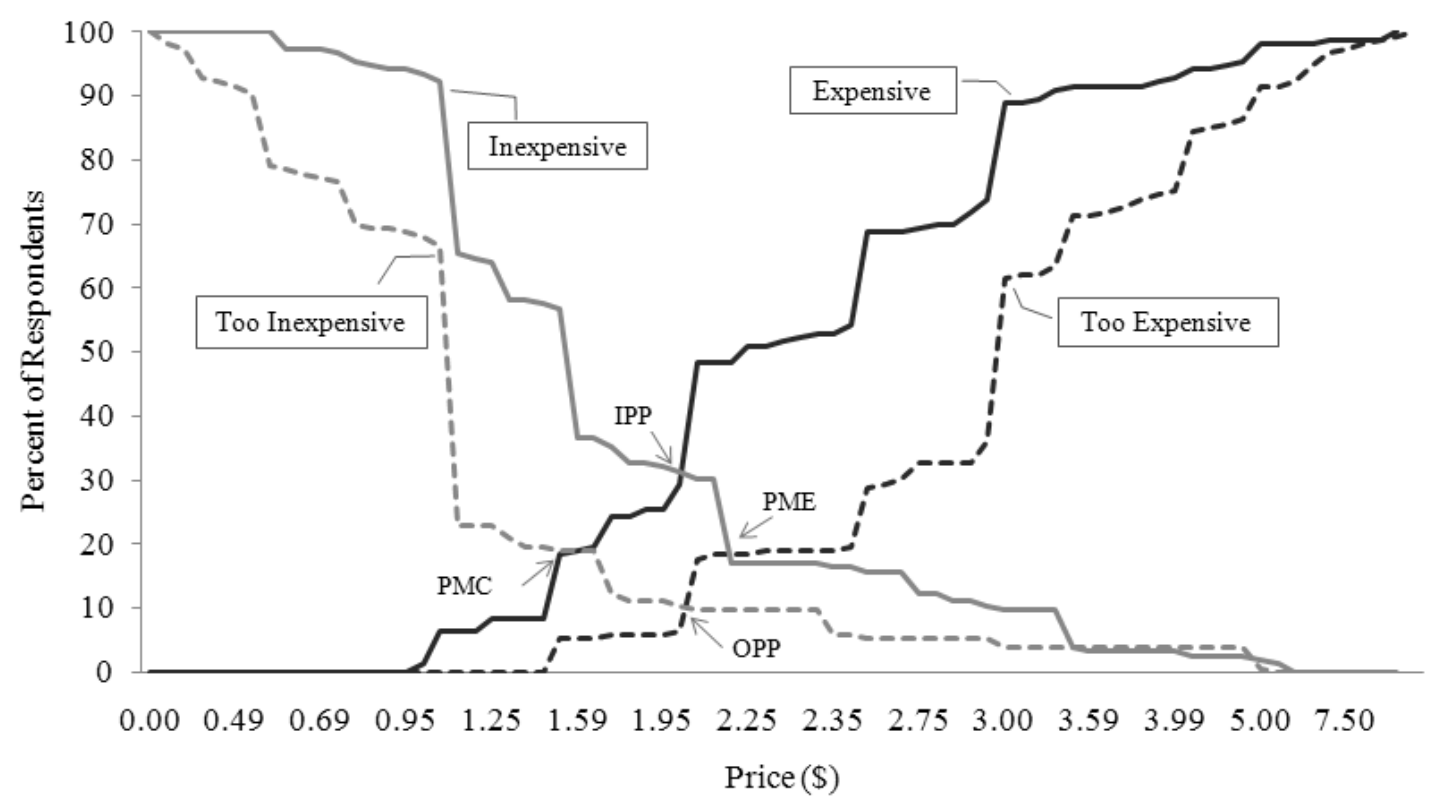

Figure 2. Acceptable price range for total observations 


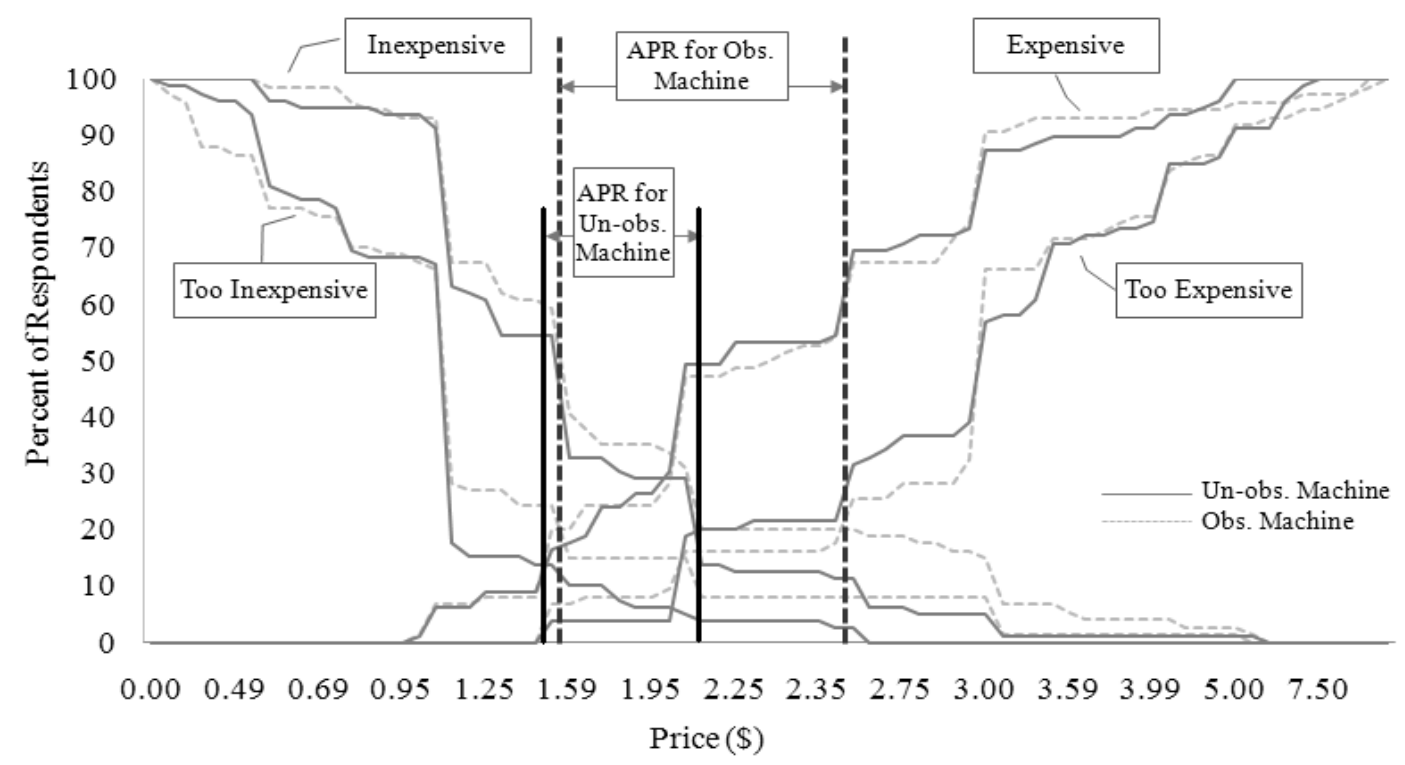

Figure 3. Acceptable price range (APR) for observed and unobserved groups

\section{Appendix}

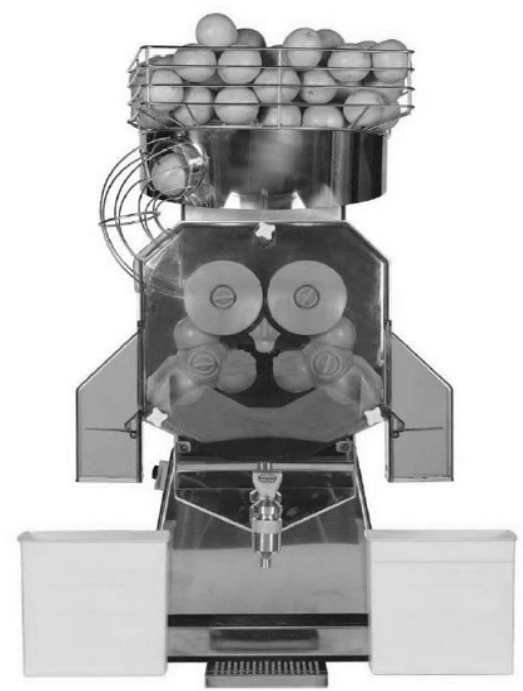

Table-top juicer 